\title{
Field study of age-differentiated strain for assembly line workers in the automotive industry
}

\author{
Kerstin Börner ${ }^{\mathrm{a},{ }^{*}}$, Christian Scherf $^{\mathrm{a}}$, Bianca Leitner-Mai ${ }^{\mathrm{a}}$ and Birgit Spanner-Ulmer ${ }^{\mathrm{a}}$ \\ ${ }^{a}$ Professorship of Human Factors and Ergonomics, Chemnitz University of Technnology, Erfenschlager Str 73, \\ 09125 Chemnitz, Germany
}

\begin{abstract}
A field study in an automotive supply industry company was conducted to explore age-differentiated strain of assembly line workers. Subjective and objective data from 23 female workers aged between 27 and 57 years were collected at the workplace belt buckle assembly during morning shifts. Subjects with medication or chronic diseases affecting heart rate and breath rate were excluded. For subjective data generation different questionnaires were used. Before the Work Ability Index and the Munich Chronotype Questionnaire were completed by the subjects. Short questionnaires (strain-ratings, NASA-TLX) directly at begin and end of the work were used for obtaining shift-related data. During the whole shift (6 a.m. -2.45 p.m. $)$ bodily functions were logged with a wireless chest strap. In addition, the motion of the hand-arm-system was recorded for 30 times, 3 minutes each after a fixed time-schedule. First results show that younger subjects need significant less time for assembly $($ mean $=14.940 \mathrm{~s})$ compared to older subjects $($ mean $=17.040 \mathrm{~s} ; \mathrm{t}(472.026)=-9.278, \mathrm{p}<0.01)$.
\end{abstract}

Keywords: field study, aging, assembly, subjective and objective data

\section{Introduction}

Considering the demographic aging of Germany, by 2030 one third of the employed persons will be older than 50 years [29]. Hence, companies in Germany face both the challenge to maintain future productivity of their processes and to ensure the competitiveness of their products.

To investigate, whether decreasing physical performance influences the work process or whether work performance can be sustained through compensatory effects, will be part of this development. Empirical findings for decreasing physical performance with increasing age are available for the ability categories strength and flexibility [1,5,7,22,26,32]. Examining the neuromuscular performance, numerous analyses have confirmed a relation between age and decreasing stimulus-response time $[8,10,21,28]$. If one considers the increasing automation, the shorter cycle times and miniaturization, more importance has to be attached to neuromuscular performance [17]. In previous studies, for example, by Pierson \& Montoye (1958), it has been demonstrated that the minimum reaction time and the maximum movement speed are reached by 20 years of age, afterwards the performance values constantly deteriorate with increasing age. In addition, Cooke and colleagues (1989) showed that movements of subjects over 60 years of age become increasingly inharmonic and they more often misjudge distance (hypermetria).

Current research from the priority program „AgeDifferentiated Worksystems" also shows a decreasing movement speed with increasing age but suggests an age-independent increase of the error rate with growing subject distance [4].

Considering the state of research there are only insufficient answers in relation to an age-differentiated design of tasks and work processes [9]. Numerous studies, confirming a decreasing performance of older people, have been conducted during laboratory tests. However, it should be emphasized that isolated tests of tempo-based basic functions do not allow any

*Corresponding author. E-mail: kerstin.boerner@mb.tu-chemnitz.de 
conclusion on work performance [12,14]. Research shows that older persons perform even better in realistic planning tasks than do their younger counterparts [13]. Work performance and age do not necessarily have to show negative correlations but rather strongly depend on work demands. Various studies support this theory [20,31,34]. These studies are in agreement with assumptions of an extended stressstrain model by Rohmert (1974). Due to miscellaneous basic conditions and multi-dimensional task structures in the working world, employees are able to vary working conditions and subject-related behavior. It remains in question however, which role task demand (short-cycled, repetitive tasks with high demands on sensory motor skills) and load duration play. Thus, there is need for further research from the authors' point of view. Graf (1955) and Jong (1959) have already documented in the 1950s the higher recovery-effective time of waiting of younger employees compared to older employees because of faster working. First examinations do not give satisfying answers, which tasks are age-critical and thereby eventually leading to "losses of time". Physical performance limitations and associated losses of time can efficiently be minimized by the choice of work method. A relation between work method and execution time was outlined in studies by Gilbreth [3].

The present field study, conducted in cooperation with an automotive supplier, was carried out within the DFG priority program 1184 "Age-Differentiated Work Systems". The study itself focused on the examination whether older employees are more stressed than younger employees during an eight-hour workload at an assembly line work station. To describe and structure manual work processes, the MTMmethod (Methods-Time-Measurement) with the MTM-basic motions was employed. Furthermore, it has been analyzed to what extent employees are able to adapt to the work system through individual action regulation and whether older employees' extensive experience influences this process. The results can be used to better consider the needs of elderly people when planning and allocating work stations with high age-critical movements in future.

\section{Methods}

\subsection{Subjects}

Participants were recruited at a subcontractor in the automotive industry in Saxony (East-Germany). Due to the unequal distribution of men and women in this factory the study focused on the larger group of women. All 54 female assembly line workers from the workplace "belt buckle assembly" were invited to informative meetings during their working time and asked to participate voluntarily in the study. A prerequisite was, however, that they were trained for more than two months at the examined workplace to ensure that they are well-trained in the sense of MTM. 38 workers gave written informed consent but six left the factory before the study began. Therefore, 32 participants were sent to medical investigation (e. g. PPI-test, height, weight, discomfort of shoulder, arm and hand). However, five subjects changed their mind and refused to participate. Four workers were excluded from the study due to their medical condition or medication possibly affecting the heart frequency or breathing rate. Finally, 23 well-trained female workers aged 27 to 57 years (mean $=43.9$ years, $\mathrm{SD}=6.82$ years) without any health problems took part in the study.

\subsection{Workplace}

The "belt buckle assembly" was chosen within the plant of the cooperation partner from the automotive supply industry for observation at the workplace because many of the performing tasks are age-critical MTM-basic motions of the hand-arm-system (see Fig. 1). An analysis of age-related changes of human abilities (e. g. vision) based on the "Chemnitz Age Database" [19] in alliance with the MTM-basic motions (e. g. reach) was carried out previously. The singlework-stations were arranged in two groups of four surrounded by a common assembly line to take completed pieces off. As a group the subjects had to assemble a given number of belt buckles within an eight-hour shift but where free to determine their individual working speed. Four workplaces were watched simultaneously. Two workplaces were chosen from each group to ensure that assembly worker were exempted from restocking the basic modules and research technique did not interfere with the production process.

Investigated workplaces were named $\mathrm{A} / \mathrm{B}$ and $\mathrm{C} / \mathrm{D}$ for data acquisition. The data presented in this paper are obtained from workplaces $\mathrm{C}$ and $\mathrm{D}$. Nine several types of belt buckles were assembled at both identical workplaces $\mathrm{C}$ and $\mathrm{D}$. About 9 to 11 single pieces were assembled manually. The workers were either sitting or standing in front of an assembly desk which was documented. In front of the workers were several small load carriers with the single pieces arranged. 


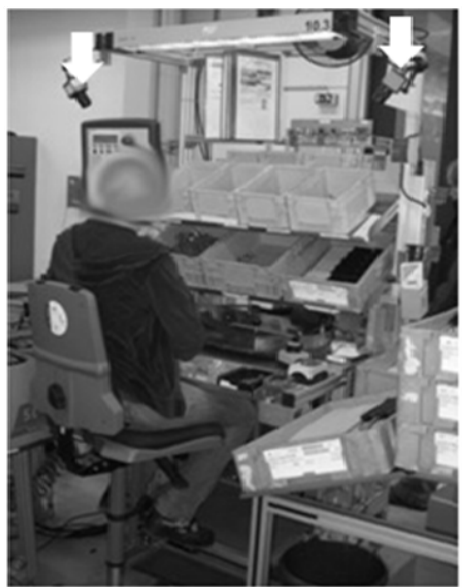

Fig. 1 Workplace belt buckle assembly (No. D), position of cameras is shown by white arrows

The stock above was filled up by Kanban-System as well as the pre-mounted basic modules provided on the right-hand side. The belt buckles were assembled on the desk in about 35 seconds and placed down on the continuously moving belt-conveyor on the left-hand side.

To record the motions of the hand-arm-system two cameras were attached at each workplace. Four workplaces were equipped with cameras and could be viewed at the same time.

\subsection{Instruments}

\subsubsection{Objective measurements}

The Aquila-Complete-System for motion recording consists of two linked computers accessing eight synchronized cameras. The software was developed specifically for this study by FusionSystems. A certain time schedule was defined to record automatically the sequences of operation 30 times per shift (distributed evenly over the shift, breaks were considered) with a duration of three minutes each. Additional manual recording was possible. Four workplaces were monitored at the same time. The videos documented the mode of operation and showed whether the production process was running smoothly.

Two experimenters were present to observe the full eight-hour shift. The observation protocols completed by the experimenters include information about changes of the belt buckle type and further, concerning the subject, conversations, briefly leaving the workplace or strenuous movements during regu- lar assembling. Every hour temperature and the average noise of a five-minute-period were notated. A $433 \mathrm{MHz}$ Temperature Station and a calibrated handheld analyser for noise level measurement from Brüel \& Kjaer version 2250-L were used for this purpose.

The bodily functions heart rate and breathing rate were logged once per second with the wireless Bioharness $^{\mathrm{TM}}$ chest strap from Zephyr ${ }^{\mathrm{TM}}$ during the entire morning shift.

\subsubsection{Questionnaire data}

Different questionnaires were used to collect subjective data. The Work Ability Index was determined by the short-form of WAI [16] and filled in at home and brought to the medical investigation. The maximal possible score was 49 points. By means of strain-ratings [23] and TLX (NASA Task Load Index) [15], the individual subjective strain was measured at the day of investigation. The strain-ratings included 12 items and were completed shortly before and after the shift and showed the degree of the actual strain on a scale from 1-6. The TLX contained 7 items which were asked after the shift and the answers were a measurement for the past strain during the observed shift (scale $0-20$ ). The individual chronotype was detected with the MCTQ (Munich Chrontype Questionnaire) [25] which was completed at home.

\subsection{Procedure}

Data were gained within nine weeks from January to March 2011 during ongoing production. For all subjects, observation and measurements were carried out at least twice during entire morning shifts $(6$ a.m. -2.45 p.m.) without disturbance of the production process. The subjects completed the strain-ratings shortly before the shift in a separate room. Afterwards, the chest strap was activated and fixed around the subject's chest underneath the clothes. The subjects went to their workplaces and fulfilled their normal assembly work wearing the comfortable strap over the next nine hours, which means during working time and breaks. After $4-4.5$ hours the logging unit at the chest strap was displaced by a fully charged logging unit. Movements of the hand-armsystem were recorded with the cameras for the 30 defined checkpoints distributed over the whole shift. After the shift the chest strap was detached, data were transferred to a computer and straps were washed for sanitary reasons. The subjects were asked to complete the strain-ratings a second time and for 
additional information the TLX. The WAI and the MCTQ were filled in at home some other day.

\subsection{Analysis}

Bodily function values from the chest strap were transferred in an excel chart, synchronized with the 30 recorded checkpoints and analyzed. Within each video check point of three minutes 5-6 belt buckles were assembled. Within each motion recording, showing regular work, the assembly of one belt was randomly selected for analysis. Data of times with irregular work, e. g. distraction through conversation were not analyzed. The two greatest common denominators of the watched movements of the handarm-systems (MTM-motions) were analyzed and compared between two age-groups. Period No. 1 covered seven basic MTM cycles, period No. 2 three basic MTM cycles with pressing in one cycle. Data presented in this paper refer to period No. 1. The assembly time required for period No.1 within the belt buckle (compare 2.2 workplace) was determined with the video records.

For identification of the individual variance in mode of operation sequence of assembly, arrangement of load carriers and other noticeable behavior, e. g. storing two different sorts of single pieces in one carrier, was recorded. Subjects were free to choose a sitting or standing working position.

Observation protocols were used to verify the equal working conditions due to temperature and noise for all days of data acquisition. Furthermore the nonworking times were analyzed.

The 23 subjects were divided in two age groups as Table 1 shows.

Statistical analyses of the data were made with the SPSS $^{\circledR}$ Predictive Analytics Software $\left(\mathrm{PASW}^{\circledR}\right.$ Statistics 18.0.0).

The t-test was used to find significant differences and correlation coefficients (r) were calculated. In addition, partial correlation Pearson chi-square-test and Fisher's exact test was employed. All p values are reported as significant at less than 0.05 .

\section{Results}

Subjects who were accredited to take part at the study had no significant difference referring to BMI (body mass index) (see Table 1). The work ability index (WAI) of younger and older women is "good" (good $=37-43$ points; [16]) with no significant difference within the groups (see Table 1). The younger group $($ mean $=1.585)$ achieved a significantly higher value of PPI (pulse-performance-index) than the older group $($ mean $=1.270 ; \mathrm{t}(21)=2.450, \mathrm{p}=0.023)$ (see Table 1).

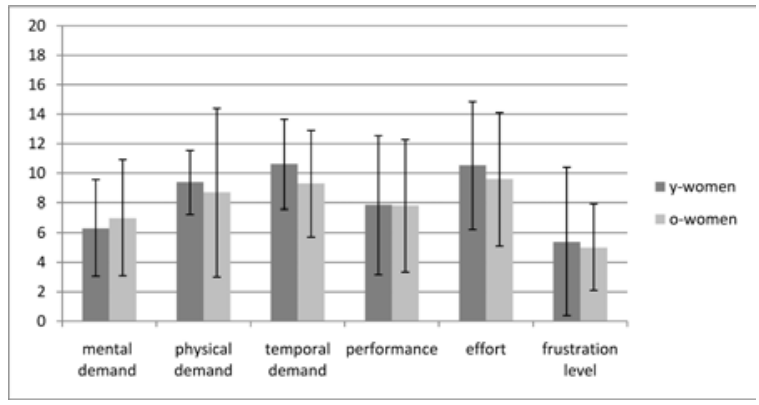

Fig. 2 Results of Task Load Index (TLX)

Both the score of the TLX and the single items showed no significant differences between the younger and the older group (see Fig. 2). For all subjects temporal demand $($ mean $=10.04)$ was perceived higher than mental demand (mean $=6.61$; $\mathrm{t}(22)=-3.875, \mathrm{p}=0.001)$. Physical demand (mean $=9.09)$ was also experienced higher than mental demand $($ mean $=6.61 ; \mathrm{t}(22)=-3.007, \mathrm{p}=0.006)$.

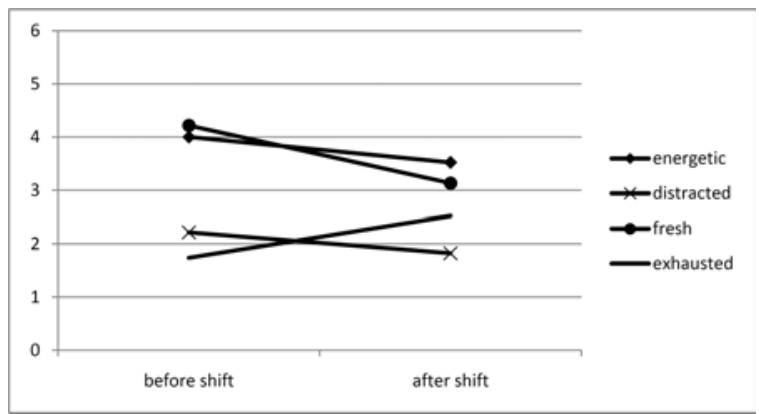

Fig. 3 Significant strain ratings of subjects before and after shift

Altogether there was a significant difference between all subjects in strain-ratings before and after shift. Subjects assessed their mood within a range from 1 (not at all) to 6 (very). All subjects felt less energetic $(\mathrm{t}(22)=2.307, \mathrm{p}=0.031)$, less distracted $(\mathrm{t}(22)=2.398, \mathrm{p}=0.025)$, less fresh $(\mathrm{t}(22)=4.204$, $\mathrm{p}<0.01)$ and more exhausted $(\mathrm{t}(22)=-2.657$, $\mathrm{p}=0.014$ ) after the shift (see Fig. 3).

Two out of 12 items of the strain-ratings displayed a significant difference due to age. The older women stated to be more unsure $($ mean $=1.80)$ at begin of the shift than did the younger women (mean $=1.15$; $t(21)=-2.095, p=0.048)$. While the energy level 
before and after the shift remained stable for older women, it declined for the younger. After the shift the younger women $($ mean $=3.08)$ felt less energy than did the older women (mean = 4.10; $\mathrm{t}(21)=-2.640, \mathrm{p}=0.015)$ (see Fig. 4).

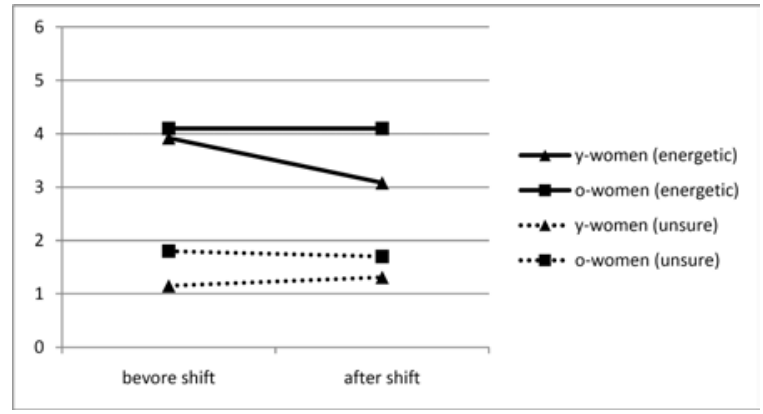

Fig. 4 Significant strain ratings of younger and older women before and after shift

Most of the subjects (75.04\%) were sitting during the measurement, but there was no difference in sitting or standing between younger and older women (Fisher's exact test: $\mathrm{p}=0.325)$. Depending on age there was no significant difference in the mode of operation (sequence of assembly, arrangement of load carriers, storing).

The following results reflect the findings regarding average assembly time of period No. 1 . The younger women $($ mean $=14.940 \mathrm{~s})$ needed in comparison less average time for assembly than the older women $($ mean $=17.040 \mathrm{~s} ; \mathrm{t}(472.026)=-9.278, \mathrm{p}<0.01)($ see Fig. 5). On closer examination of the younger group there is a correlation between average assembly times and nonworking times $(\mathrm{r}=-0.622, \mathrm{p}=0.023)$.

There is a correlation between age and average assembly time $(\mathrm{r}=0.592, \mathrm{p}<0.01)$ and age and MCTQ $(\mathrm{r}=-0.52, \mathrm{p}=0.011)$. A partial correlation of age and average assembly time with the covariate MCTQ showed a significant correlation $(\mathrm{r}=0.567, \mathrm{p}<0.01)$. Fishers exact test was used to show the distribution of chronotypes between younger and older women ( $p$ $=0.286)$. There is no correlation between average assembly time and WAI, BMI, arm discomfort und shoulder discomfort but there is a correlation between hand discomfort and average assembly time $(\mathrm{r}=0.532, \mathrm{p}<0.01)$. Fisher's exact test $(\mathrm{p}=0.214)$ was used to state the equal distribution of hand discomfort of younger and older women.

\section{Discussion}

The aim of this field study was to investigate women of different age who are quite similar in their preposition but only differ in age. The results of WAI, TLX and BMI show, the investigated subjects are a homogeneous group in this regard. The work ability is "good" for all subjects and does not differ significantly between both age groups. Results of the TLX indicate the similar subjective appraisement of work and the results of BMI show subjects' similar physical conditions. Despite the differences in PPI, a PPI > 1 is still good for both groups [27].

The results of strain ratings before and after shift show the influence of work to all subjects. Independent of age they felt less energetic, less distracted, less fresh and more exhausted after work. The older women's constant energy level before and after the shift may result from the slower working speed. The younger women were more than $12 \%$ faster than the older ones in the average assembly time and they felt less energetic after the shift. As the results show, there is an age dependent difference in average assembly times between younger an older women. The differences in assembly time could be ascribed to the fact that there was no time pressure in the assembly through work cycle, so the women were free in determining their individual working speed. The correlation between average assembly time and nonworking times among the younger subjects indicate that they use their fast working speed to acquire additional breaks of work. Due to assembly times detailed analysis is under examination. Heart frequency was used as an indicator for the objective strain, because it could be registered without influencing the working process. This condition was an essential requirement to conduct the field study. Analysis is still in progress.

It is critically noted that the sample with 23 women is relatively small and the distribution of age is not ideal. The age of the women was distributed unequally with the majority of the women being in their midfourties. Therefore, no young women $<27$ years could be investigated.

In conclusion, more additional data to consolidate the findings and the complex interrelations of age and work are necessary. 
Table 1

Mean values $( \pm \mathrm{SD})$ of data gained in the medical examination for younger $(\mathrm{y})$ and older $(\mathrm{o})$ women

\begin{tabular}{llllllll} 
& $\mathrm{n}$ & Age (years) & Weight $(\mathrm{kg})$ & Hight $(\mathrm{m})$ & BMI $\left(\mathrm{kg} / \mathrm{m}^{2}\right)$ & WAI (points) \\
\hline Y-Women & 13 & $39.7 \pm 4.44$ & $67.8 \pm 10.83$ & $1.672 \pm 0.0572$ & $24.3 \pm 4.23$ & $37.5 \pm 5.43$ \\
\hline $\mathrm{O}$-Women & 10 & $49.4 \pm 5.32$ & $75.1 \pm 15.33$ & $1.651 \pm 0.0420$ & $27.5 \pm 5.20$ & $38.6 \pm 4.99$ \\
\hline & & &
\end{tabular}

Fig. 5 Different average assembly times of younger and older women

\section{References}

[1] C.J. Barnes, S.J. Van Steyn and R.A. Fischer, The effects of age, sex, and shoulder dominance on range of motion of the shoulder. Journal of Shoulder and Elbow Surgery 10 (2001), 242-246.

[2] J.E. Birren, and J. Botwinick, Speed of response as a function of perceptual difficulty and age. Journal of Gerontology 10 (1955), 433-436.

[3] R. Bokranz and K. Landau, Produktivitätsmanagement von Arbeitssystemen. Stuttgart: Schäffer-Poeschel Verlag 2006.

[4] J. Bützler, S. Vetter, N. Jochems and C.M. Schlick, Refinements of Fitts' Law for large touch screens: age-differentiated analysis of the motion angle in bivariate pointing tasks, in: M. Goebel, C.J. Christie, S. Zschernack, A.I. Todd and M. Mattison, eds., Research for the missing link. 10th International Symposium on Human Factors in Organisational Design and Management, Vol. 2. Santa Monica, CA: IEA PRESS 2011, pp. 93-99

[5] E. Chateauroux and X. Wang, (2008). Effects of age, gender, and target location on seated reach capacity and posture. $\mathrm{Hu}-$ man Factors 50 (2008), No. 2, 211-226.

[6] J.D. Cooke, S.H. Brown and D.A. Cunningham, Kinematics of arm movements in elderly humans. Neurobiology of Aging 10 (1989), 159-165.

[7] N. Doriot and X. Wang, Effects of age and gender on maximum voluntary range of motion of the upper body joints. Ergonomics 49 (2006), No. 3, 269-281.

[8] J.L. Fozard, M. Vercruyssen, S.L. Reynolds, P.A. Hancock and R.E. Quilter, Age Differences and changes in reaction time: the Baltimore longitudinal study of aging. Journal of Gerontology 49 (1994), No. 4, 179-189.
[9] E. Frieling, M. Buch and J. Wieselhuber, Alter(n)sgerechte Arbeitssystemgestaltung in der Automobilindustrie - die demografische Herausforderung bewältigen, Zeitschrift für Arbeitswissenschaft 60 ( 2006), 213-219.

[10]R. Gottsdanker, R., Age and simple reaction time. Journal of Gerontology 37 (1982), No. 3, 342-348.

[11] O. Graf, Studien über Arbeitspausen in Betrieben bei freier und zeitgebundener Arbeit (Fließarbeit). Forschungsberichte des Wirtschafts- und Verkehrsministeriums NordrheinWestfalen, Nr. 11, Köln: Westdeutscher Verlag 1955.

[12]W. Hacker (ed), Erwerbsarbeit der Zukunft - auch für „Ältere"? Zürich u. a.: vdf Hochschulverlag AG 1996.

[13]W. Hacker , I. Auerbach, E. Hagendorf and M. Rudolf, Erfüllen zurückgestellter zeitbezogener Aufträge - selbstinduziertes Nutzen von Abrufhilfen. Zeitschrift für Experimentelle Psychologie 46 (1999), 81-106.

[14]W. Hacker, W. (2003). Leistungsfähigkeit und Alter. Kolloquium „Praxis trifft Wissenschaft“ des Instituts für Arbeitsmarkt und Berufsforschung unter dem Titel „Eine Frage des Alters - Herausforderungen für eine zukunftsorientierte Beschäftigungspolitik." Abgerufen am 02.08.2011 unter http://doku.iab.de/grauepap/2003/lauf_hacker_vortrag.pdf

[15] S.G. Hart and L.E. Staveland, Development of a NASA-TLX (Task Load Index): Results of empirical and theoretical research, in: P.A. Hancock and N. Meshkati, eds., Human mental workload, Amsterdam: North-Holland 1988, pp. 139-183.

[16]H.M. Hasselhorn and G. Freude, Der Work ability Index - ein Leitfaden, Bundesanstalt für Arbeitsschutz und Arbeitsmedizin, ed., Wirtschaftsverlag NW, Bremerhaven 2007

[17] M. Hegele and H. Heuer, Sensomotorische Adaptation und Erwerbsalter, in: Kompetenzentwicklung in realen und virtuellen Arbeitssystemen. 53. Kongress der Gesellschaft für Arbeitswissenschaft, Otto-von-Guericke-Univ., Fraunhofer - IFF Magdeburg, Gesellschaft für Arbeitswissenschaft, ed., GfAPress, Dortmund, 2007, pp. 789-792 
[18]J.R. Jong, J. R., Leistungsminderung im vorgerückten Alter. Zeitschrift für Arbeitswissenschaft und Fachberichte aus der sozialen Betriebspraxis 13(1959), 136-140.

[19] M. Keil, B. Spanner-Ulmer and C. Scherf, Änderungen der menschlichen Leistungsfaktoren im Alter - Entwicklung eines interdisziplinären Altersmodells. Frühjahrstagung der Gesellschaft für Arbeitswissenschaft, Dortmund: GfA Press 2009, pp. 145-148.

[20] G.M. McEvoy and W.F. Cascio, Cumulative evidence of the relationship between employee age and job performance, Journal of Applied Psychology 74 (1989), 11-17.

[21]W.R. Pierson and H.J. Montoye, Movement time, reaction time, and age. Journal of Gerontology 13 (1958), No. 4, 418421.

[22]M.M. Porter A.A. Vandervoort and J. Lexell, Aging of human muscles: structure, function and adaptability. Scandinavian Journal of Medicine \& Science in Sports 5 (1995), 129-142.

[23]P. Richter, U. Debitz and F. Schulze, Diagnostik von Arbeitsanforderungen und kumulativen Beanspruchungsfolgen am Beispiel eines Call Centers. Zeitschrift für Arbeitswissenschaft 56 (2002), 1-2, 67-76.

[24]W. Rohmert, Das Belastungs-Beanspruchungs-Konzept. Zeitschrift für Arbeitswissenschaft 38 (1984), 193-200.

[25] T. Roenneberg, A. Wirz-Justice and A. Merrow, Life between clocks: Daily Temporal Patterns of Human Chronotypes. Journal of Biological Rhythms 18 (2003), 80-90.

[26]M. Runge, M. Rittweger, J., Russo, C. R., Schiessl, H. and D. Felsenberg, Is muscle power output a key factor in physical performance? A comparison of muscle cross section, chair rising test and jumping power. Clinical Physiology and Functional Imaging 24 (2004), No. 6, 335-340.

[27]R. Seibt, D. Dutschke, A. Hübler and K. Scheuch, Handlungsanleitung zur Durchführung einer individuellen Vorsorgediagnostik für Lehrkräfte - Das Dresdner Modell, -r. Seibt, ed., Selbstverlag der TU Dresden, Dresden 2007

[28]W.W. Spirduso and P. Clifford, Replication of age and physical activity effects on reaction and movement time. Journal of Gerontology 33 (1978), No. 1, 26-30.

[29]Statistische Ämter des Bundes und der Länder (Hrsg.) (2007) Demografischer Wandel in Deutschland - Bevölkerungs- und Haushaltsentwicklung im Bund und in den Ländern. Wiesbaden: Statistisches Bundesamt.

[30]H.Tanaka, K.D. Monahan and D.R. Seals, Age-predicted maximal heart rate revisited, J. Am. Coll. Cardiol. 37 (2001), $153-156$

[31]C. Tesch-Römer, Produktivität im Alter. In Deutsches Zentrum für Altersfragen, eds., Informationsdienst Altersfragen. Heft 03, Jg. 33 (2006), 2-5.

[32]J.T. Viitasalo, P. Era, A.-L. Leskinen and E. Heikkinen, (1985). Muscular strength profiles and anthropometry in random samples of men aged 31-35, 51-55 and 71-75. Ergonomics 28 (1985), No. 11, 1563-1574.

[34]D.A.Waldman and B.J. Avolio, A meta-analysis of age differences in job performance, Journal of Applied Psychology 71 (1986), 33-38. 